\title{
The potential of active fiber composites made from piezoelectric fibers for actuating and sensing applications in structural health monitoring
}

\author{
A. J. Brunner, M. Barbezat, Ch. Huber and P. H. Flüeler \\ Empa, Swiss Federal Laboratories for Materials Testing and Research, Laboratories for Polymers \& Composites, \\ Überlandstrasse 129, CH-8600 Dübendorf, Switzerland
}

Received: 5 November 2004; accepted: 12 January 2005

\begin{abstract}
Active Fiber Composites made from piezoelectric fibers were originally developed as actuators for adaptive materials systems. Their properties, however, also allow their use as sensor or emitter-receiver in various applications. After presenting selected characteristics, the potential of Active Fiber Composites for structural health monitoring is discussed in comparison with that of conventional piezoelectric elements.

1359-5997 (C) 2005 RILEM. All rights reserved.

\section{RÉSUMÉ}

Des Composites à Fibres Actifs constitués de fibres piézo-électriques ont été développés initialement comme actuateurs pour des systèmes adaptifs. Les propriétés des Composites Actifs à Fibres permettent également leur application comme capteur ou émetteurcapteur. Après une discussion de certaines de leurs caractéristiques, le potentiel des Composites à Fibres Actifs pour le contrôle de santé structurale sera discuté en comparaison avec des éléments piézo-électriques conventionnels.
\end{abstract}

\section{INTRODUCTION}

Active Fiber Composites (AFC) originally developed by Bent and Hagood [1] consist of unidirectionally aligned piezoelectric fibers sandwiched between two layers of interdigitated electrodes that have been screen-printed on thin polyimide films (Fig. 1). AFC were mainly intended for actuation or deformation of adaptive elements or structures [2]. However, model experiments with $\mathrm{AFC}$ integrated into or surface mounted on fiber-reinforced laminates have shown that application as acoustic emission (AE) sensor [3, 4], as emitterreceiver pair for acousto-ultrasonic (AU) [5], or as strain gauge, even though in a limited deformation range [6], are also feasible.

In this contribution, the potential of AFC as sensors or emitters for monitoring the integrity of structures or of infrastructure (so-called structural health monitoring [7], SHM for brevity) will be discussed. The main aim is to identify areas of application that look promising for developing prototype SHM systems with AFC elements.

\section{PROPERTIES AND CHARACTERISTICS OF AFC}

In the following, the discussion will be limited to piezoelectric elements for SHM. A quantitative comparison of AFC with sensors based on other physical principles, e.g., fiber optics or micro-electro-mechanical systems (MEMS) [7] would be desirable. However, even an experimental comparison between $\mathrm{AFC}$ and planar PZT-sensor elements such as thin wafers [8] or so-called macro-fiber composites (MFC) [9] is still lacking.

Even though piezoelectric sensors can be manufactured from a variety of materials, lead-zirconate-titanate (PZT) seems to dominate research on piezoelectric sensors for SHM [7]. Resonant $\mathrm{AE}$ sensors are selected as benchmark in the comparison with AFC, since within the last two years a certain amount of quantitative data applying different characterization methods has accumulated $[3-5,10]$.

The commercial PZT-fibers for manufacturing AFC had diameters around $250 \mu \mathrm{m}$ and a length of $150 \mathrm{~mm}$ [11].

\footnotetext{
Editorial note

Empa is a RILEM Titular Member.
} 
Leaving possible multiple layers or stacks of piezoelectric fibers aside, the size of AFC is currently limited by the fibers available to a length of $150 \mathrm{~mm}$ or less, a thickness of typically $0.3 \mathrm{~mm}$ and a width determined by the number of fibers and their spacing. The maximum width may be limited by the screen-printing process for the electrodes to about $160 \mathrm{~mm}$; unless other concepts, e.g., sputtering or other coating processes are used for the electrodes. Screen-printing the electrodes may hence also pose limits on the maximum length of AFC, once longer fibers become available. The minimum width of active area realized at Empa to date is $5 \mathrm{~mm}$, i.e., about 20 fibers. The longest AFC manufactured at Empa to date (Fig. 1) measured overall $125 \mathrm{~mm} \times 41 \mathrm{~mm} \times 0.3 \mathrm{~mm}$ (active area defined by the size of the electrodes of $101 \mathrm{~mm} \mathrm{x}$ $14 \mathrm{~mm}$, i.e., about 52 fibers, each $118 \mathrm{~mm}$ long). The minimum size is currently set by the screen-printed electrodes. Typically, electrode width is $0.2 \mathrm{~mm}$, the minimum electrode distance realized at Empa so far is $0.4 \mathrm{~mm}$, and the minimum length of an AFC is hence estimated to be around $1 \mathrm{~mm}$ (active fiber length $0.8 \mathrm{~mm}$ ) with current technology. AFC with a length of about $6 \mathrm{~mm}$ have been realized at Empa. Within certain limits, AFC elements can be tuned to a specific frequency range of main sensitivity and emissivity. For conventional $\mathrm{AE}$ sensors, frequency tuning after manufacturing is not possible.

Typical characteristics will now be presented for AFC with an overall size of $30 \mathrm{~mm} \times 40 \mathrm{~mm} \times 0.3 \mathrm{~mm}$ (active area of about $20 \mathrm{~mm} \times 30 \mathrm{~mm}$ ), i.e., about 70 fibers, and an electrical capacitance (at $1 \mathrm{kHz}$ ) around $1 \mathrm{nF}$.

Impedance measurements (impedance analyzer type HP4194A, $100 \mathrm{~Hz}$ to $1 \mathrm{MHz}$, step size $2 \mathrm{kHz}$ ) as a function of frequency are shown in Fig. 2. The dominant peaks in the curves indicate that the sensitivity of the AFC depends

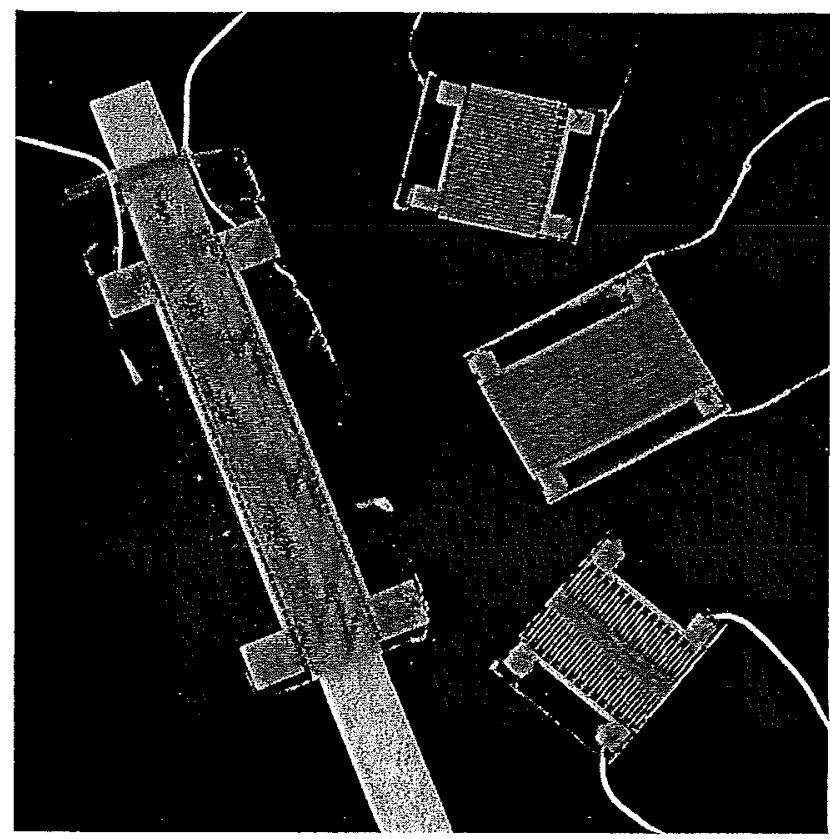

Fig. 1 - Photograph of different types of Active Fiber Composites manufactured at Empa, the $125 \mathrm{~mm}$ long element on the left has been mounted on a glass-fiber reinforced beam. The length of the other elements is $30 \mathrm{~mm}$ and $45 \mathrm{~mm}$, respectively. The width of the active area of the element near the bottom right hand corner is $5 \mathrm{~mm}$. on the fiber length and have, so far, been varied between about $30 \mathrm{kHz}$ and $270 \mathrm{kHz}$ [10]. Width and spacing of the interdigitated electrodes may limit the selection of a particular frequency. The bandwidth from the impedance measurements is in the range between $19 \%$ and $23 \%$.

The sensitivity of the sensing element is a crucial property for all SHM applications. As an example, the sensitivity of $\mathrm{AFC}$ is compared with that of conventional AE sensors using commercial AE equipment (AMS-3 from Vallen Systeme $\mathrm{GmbH}$ ). Band-pass frequency filtering between $30 \mathrm{kHz}$ and 1 '000 kHz is applied (lower limits of 30 or $95 \mathrm{kHz}$ are available in the AE equipment). Fig. 3 shows the amplitudes of simulated AE signals, i.e., pencil breaks, so-called Hsu-Nielsen sources ([12], p. 41) as a function of distance for a $45 \mathrm{kHz}$ displacement/velocity $\mathrm{AE}$ sensor (acting as displacement sensor below $45 \mathrm{kHz}$ ) and an $\mathrm{AFC}$, both applied to a $3 \mathrm{~mm}$ thick aluminum plate. Fig. 4

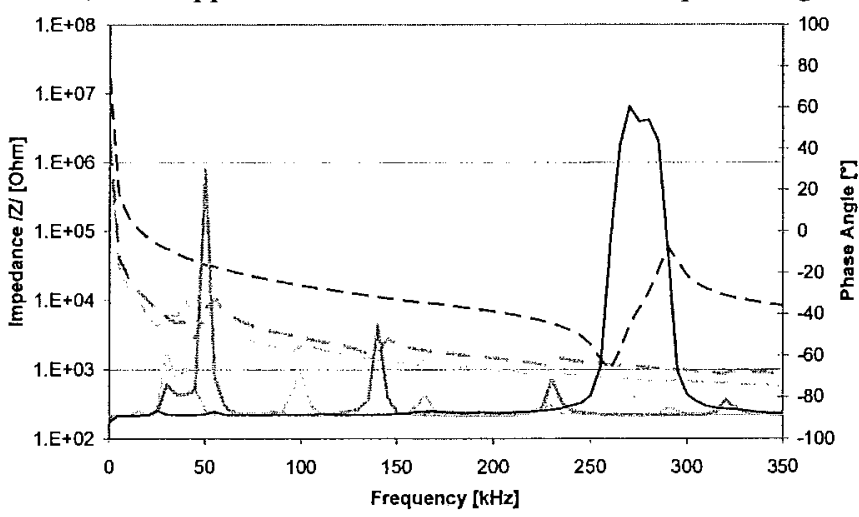

Fig. 2 - Impedance (absolute value /ZJ, dotted lines, and phase angle, solid lines) as a function of frequency between $100 \mathrm{~Hz}$ and $1,000 \mathrm{kHz}$ recorded with a scan step size of $2 \mathrm{kHz}$ for three different types of Active Fiber Composites, all with electrode width around $0.2 \mathrm{~mm}$ and electrode spacing of $0.9 \mathrm{~mm}$.

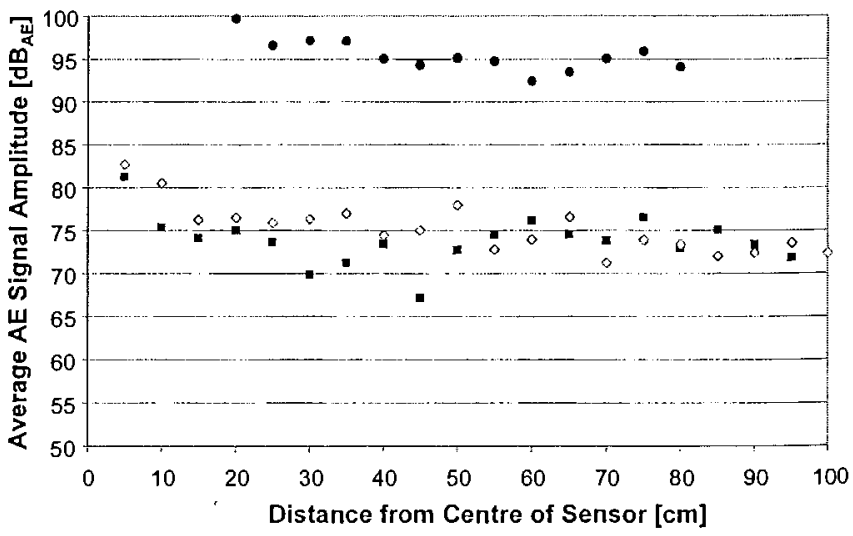

Fig. 3 - AE signal amplitudes (averages from at least four AE signals, standard deviations typically $\pm 1.5 \mathrm{~dB}_{\mathrm{AE}}$ ) from simulated $\mathrm{AE}$ signals applied on an aluminum plate as a function of the distance between source and sensor, recorded with Active Fiber Composite (filled squares = paraliel to fiber direction, open diamonds = normal to fiber direction), and a commercial AE sensor type SE45-H from Dunegan Engineering Corporation Inc. (open circles), all signals have been recorded with a $30-1,000 \mathrm{kHz}$ band-pass frequency filter. The signals recorded with the $\mathrm{AE}$ sensor below $20 \mathrm{~cm}$ exceeded the dynamic limit of the equipment. The average attenuation of roughly $5 \mathrm{~dB}_{\mathrm{AE}} / \mathrm{m}$ in the far-field distance $(>20 \mathrm{~cm})$ is similar for $\mathrm{AFC}$ and $\mathrm{AE}$ sensor. 


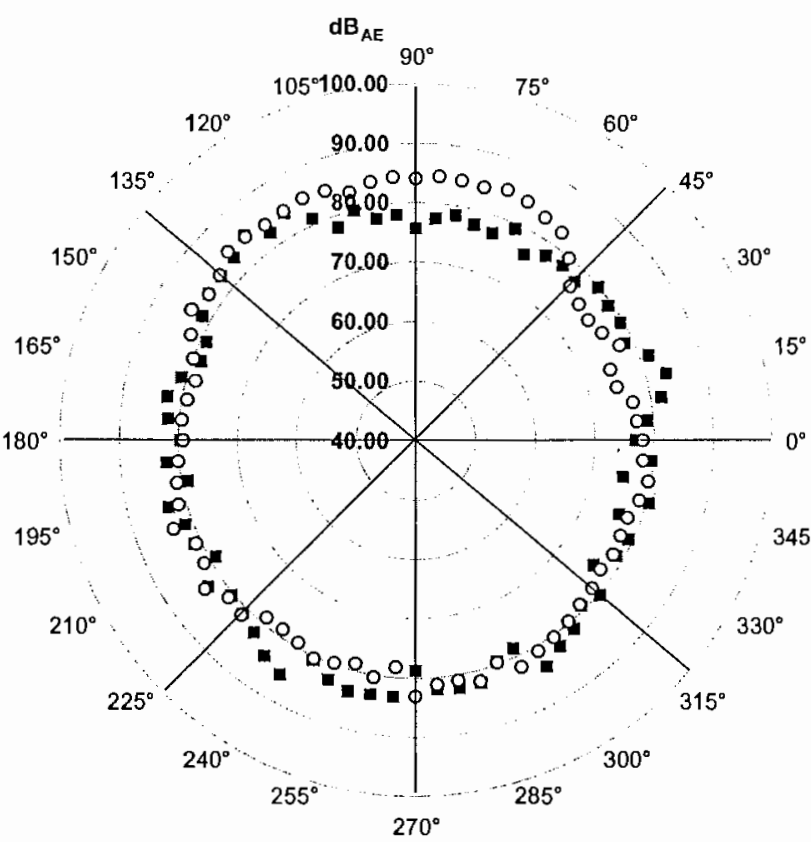

Fig. 4 - AE signal amplitudes (averages from at least four simulated $\mathrm{AE}$ signals, standard deviations typically $\pm 1.5 \mathrm{~dB}_{\mathrm{AE}}$ ) applied on a polymethyl-methacrylate plate at $5^{\circ}$ steps of the polar angle and $40 \mathrm{~cm}$ from the sensor recorded with Active Fiber Composite (filled square symbols), and compared with a commercial AE sensor type SE45-H from Dunegan Engineering Corporation Inc. (open circles), the lines indicate the respective standard deviations, all signals have been recorded with a $30-1,000 \mathrm{kHz}$ band-pass frequency filter. Both, Active Fiber Composite and $\mathrm{AE}$ sensor yield comparable, within the standard deviations isotropic, sensitivity patterns. The estimated attenuation of $50 \mathrm{~dB} A \mathrm{AE}$ is similar for $\mathrm{AFC}$ and $\mathrm{AE}$ sensor and significantly higher than in aluminum (see Fig. 3).

shows a polar diagram as a function of the angle between the source location and a reference direction of the sensor (fiber direction for the $\mathrm{AFC}$, arbitrary for isotropic $\mathrm{AE}$ sensor) of the amplitudes of simulated AE signals applied at a fixed distance of $40 \mathrm{~cm}$ on a poly-methacryl-methacrylate (PMMA) plate. Since most of the AE SHM considered below applies to test objects consisting of relatively thin shells, this set-up is considered sufficient for a first comparison.

Using commercial AE sensor sensitivity test equipment (Sensor Tester, type VST from Vallen Systeme GmbH) it has been shown that AFC tend to have an increased sensitivity for in-plane versus out-of-plane excitation by transient mechanical waves compared with conventional AE sensors [10]. Out-ofplane excitation of AFC and $\mathrm{AE}$ sensors has been compared in a face-to-face configuration on the VST, while in-plane excitation used mounting on an additional PMMA test piece (see [10] for details). The AFC yielded a similar response in both configurations. This is consistent with increased in-plane sensitivity of the AFC, taking the attenuation of the exciting signal by the PMMA in the in-plane case into account. This may constitute an additional advantage of the AFC when the element is laminated into or mounted onto the surface of structures such as, e.g., fiber-reinforced composites.

In actuator applications of the AFC, usually the achievable strain and/or load are maximized, requiring application of
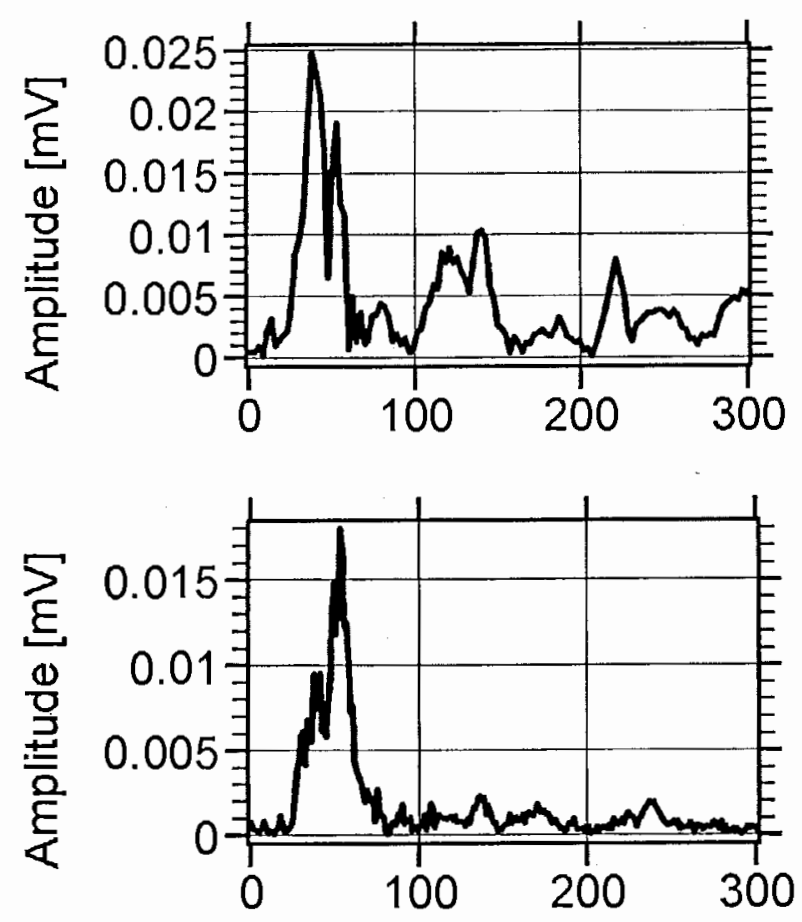

Fig. 5 - Fast Fourier Transforms ( 0 to $300 \mathrm{kHz}$ range) of waveforms emitted by Active Fiber Composite upon excitation with transient electrical pulses and recorded with a linear displacements acoustic emission sensor (type SE1000-H from Dunegan Engineering Corporation Inc.) after $30-1,000 \mathrm{kHz}$ band-pass frequency filtering, both mounted on a $3 \mathrm{~mm}$ thick polymethyl-methacrylate plate $10 \mathrm{~cm}$ apart, (top) along fiber length $\left(0^{\circ}\right)$, (bottom) normal to fiber length $\left(90^{\circ}\right)$. Normal to the fiber orientation of the AFC, the higher frequency components ( $>100 \mathrm{kHz})$ are reduced compared with the FFT recorded parallel to the fiber orientation.

high-voltage signals, typically several $\mathrm{kV}$ per mm electrode distance [13]. However, even low-voltage signals (about $60 \mathrm{~V}$ peak-to-peak is the maximum excitation delivered by the socalled auto-calibration function of $\mathrm{AE}$ equipment) are sufficient to excite transient mechanical waves in objects to which the AFC are acoustically coupled. Fig. 5 shows Fast Fourier Transforms of waveforms emitted by electric pulse excitation of $\mathrm{AFC}$ and recorded with a linear displacement $\mathrm{AE}$ transducer. AFC are hence suited as emitter-receiver pairs for $\mathrm{AU}$ applications analogous to $\mathrm{AE}$ sensors or low-frequency ultrasonic transducers. On the PMMA plate, the signals emitted by the AFC upon excitation by auto-calibration pulses of the $\mathrm{AE}$ equipment are attenuated below the detection threshold $\left(40 \mathrm{~dB}_{\mathrm{AE}}\right)$ over propagation distances around 20 to $30 \mathrm{~cm}$. On metallic test objects, AE signal attenuation with distance is much less (see Figs. 3 and 4). In order to yield useful signal propagation ranges for specific applications, AFC can be excited by pulses up to several hundred volts or more, if high-voltage amplifier sources are used. Excitation by the auto-calibration function of the AE equipment simply demonstrated proof-of-concept.

$\mathrm{AFC}$ are thin and planar, and of low weight with about $2.2 \mathrm{~g}$ total mass, and about $0.9 \mathrm{~g}$ PZT-fibers for the type presented here. Due to their sandwich laminate-type lay-up, AFC easily conform to non-planar, even bi-axially curved, 
contact surfaces. This eliminates the need for waveguide adapters for curved surfaces. So far, three mounting procedures have been used for AFC. They consist of either applying silicone-free vacuum grease as couplant and fixing the AFC with scotch tape to the test object, adhesive bonding using a commercial two-component adhesive which upon setting also provides acoustic coupling, and integrating $\mathrm{AFC}$ into fiber-reinforced laminates. Acoustic coupling in the latter two cases has been shown to be roughly equivalent [4]. The mounting of AFC on rough surfaces has not been investigated, all test objects had surface roughness suitable to mount conventional AE sensors as well. It is expected that permanent adhesive bonding of AFC could accommodate some surface roughness, even in addition to surface curvature but limits have not been explored yet.

The operating temperature range for AFC has not yet been explored; most tests have been performed at or near roomtemperature $\left( \pm 10^{\circ} \mathrm{C}\right)$. Mismatch between coefficients of thermal expansion of the various materials used in $\mathrm{AFC}$ is expected to set limits, but there is no reason why AFC could not be operated in the range between $0^{\circ} \mathrm{C}$ and about $+100^{\circ} \mathrm{C}$ (however, at constant temperature because of pyro-electric effects).

Electric shielding can be provided by, e.g., thin metallic foils in contact with common electrical ground adhesively bonded on top of the AFC, replacing the bulky metallic case of transducers by a light-weight alternative. The electrical wiring of AFC, of course, has to be considered as well. Integrating the wires into laminates has proven feasible, and surface-mount techniques for permanent bonding of wires are available but have not yet been investigated with respect to reliability and long-term behavior. Depending on the service environment wires and contacts may have to be provided with additional protection against corrosion.

\section{APPLICATION OF AFC IN ACOUSTIC EMISSION MONITORING}

Several commercially successful AE applications have been developed for proof testing or periodic inspection of objects made from fiber-reinforced polymer-matrix composites [14, $15]$ and [12, sections 7 and 12]. AE proof testing and periodic inspection of metallic pressure vessels, for e.g., storage of liquid gas [16], are examples of more recent developments.

Even though $\mathrm{AFC}$, in principle, can readily replace conventional AE sensors in any of the above applications, it is important to fully exploit the specific properties of AFC, if commercially successful applications shall be developed. Thin, light-weight and conformable AFC seem ideal as permanently mounted $\mathrm{AE}$ sensors for continuous health monitoring of thin shell-type surfaces such as, e.g., used in aircraft and space-probe applications [7]. Even though full-scale aircraft fatigue tests and even flight tests have been monitored with conventional AE sensors ([7], chapter 6), their size and shape may inhibit permanent mounting for continuous in-service monitoring. AFC may also offer solutions in certain locations, e.g., on aerodynamic surfaces, where conventional AE sensors could not be mounted without affecting the performance of the test object.

$A F C$ can further be integrated into laminates to yield structures with built-in AE sensor capability which is hardly feasible with conventional AE sensors. In that area, AFC compete with thin, planar PZT-wafers [8] but again seem at an advantage because of their conformability.

Of course, the established methods of AE analysis, whether based on AE signal parameter data sets (see, e.g., [12], p. 28) or full transient waveform recording, including Fast Fourier Transform and waveform pattern recognition or classification apply to AE signals recorded with AFC the same as for those recorded with conventional resonant or broad-band $\mathrm{AE}$ sensors $[3-5,10]$. Location of $\mathrm{AE}$ sources with $\mathrm{AFC}$ is feasible as shown by experiments with simulated AE signals (HsuNielsen sources) applied on a GFRP plate. A model experiment with $\mathrm{AFC}$ and resonant $150 \mathrm{kHz} \mathrm{AE}$ sensors on a GFRP beam has also shown that comparable assessments result from Felicity-effect analysis [3].

\section{APPLICATION OF AFC IN ACOUSTO- ULTRASONIC ASSESSMENT}

In contrast to passive $\mathrm{AE}$ monitoring, $\mathrm{AU}$ measurements are based on stress wave propagation between an emitter and a receiver, placed on the surface of the test object [17]. An advantage of the AU method is that it can yield indications of defect states and so-called "diffuse" defect populations that affect mechanical strength both, arising from processing and manufacturing, as well as from exposure to aggressive environments [18]. In fiber-reinforced composites, assessment of lateral (in-plane) properties frequently is at least as important as that of through-thickness properties [18]. AFC seem ideally suited to perform AU measurements with enhanced in-plane sensitivity [10]. Since the emitting and sensing frequency of AFC can, within certain limits, be tuned to a specific range, AFC may find a niche in Lamb wave testing, where specific frequency ranges are required to excite specific modes ([7], p. $136 \mathrm{ff}$.)

A model experiment with four AFC elements on a GFRP beam (Fig. 6) has been designed to investigate the feasibility of AU monitoring for damage accumulation in GFRP, e.g., due to impact and subsequent delamination growth. As discussed in detail in [5], guided waves emitted and received by AFC successfully indicated and discriminated several stages of damage accumulation in a GFRP beam by various empirical approaches mostly borrowed from AE data analysis, including

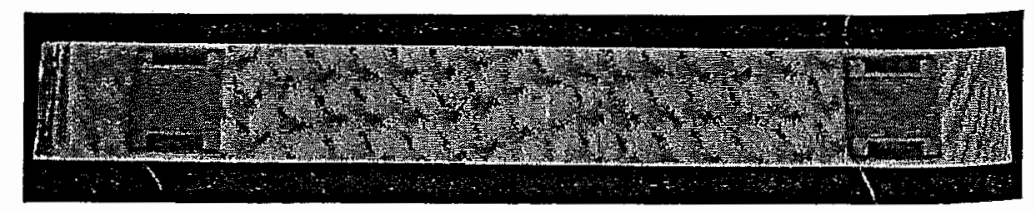

Fig. 6 - Photograph of GFRP beam (355 $\mathrm{mm}$ x $45 \mathrm{~mm}, 1 \mathrm{~mm}$ thick) used in model experiment for detection of successive stages of damage accumulation by acousto-ultrasonic measurements with four AFC. Two AFC are mounted on the top side (shown), two more on the bottom side. 
AE waveform classification (applying VisualClass software from Vallen Systeme GmbH). It is interesting to note that not only increasing damage stages could be discriminated from the initial (arbitrary) reference state but also successive stages of increasing damage from one another. This model experiment and its analysis will have to be pursued further. However, the first results indicate the potential of combining $\mathrm{AU}$ measurements with sophisticated AE waveform pattern recognition for successful SHM applications.

Before developing a prototype application, the signal-tonoise ratio, the reliability of the $\mathrm{AFC}$, and the robustness of the methods for data analysis have to be investigated in detail. Optimization of the AFC elements for the specific purpose, e.g., with respect to the frequency range, quite likely constitutes a first step. With respect to data analysis, approaches developed for conventional PZT-emitterreceiver pairs (e.g., [7], chapter 5) are applicable to AFC.

\section{ADDITIONAL CONSIDERATIONS FOR AFC USED IN STRUCTURAL HEALTH MONITORING}

AFC elements integrated as actuators into laminates also yield adaptive structures as those obtained from integration of piezoelectric wafers [19]. However, when used as sensors for SHM only, there are two arguments against integration, namely (1) effects on the mechanical properties or integrity of the structure, and (2) access for replacing failed or improperly functioning elements. Both arguments gain in importance for long-term or service-life monitoring. Therefore, whenever possible, it seems preferable to use surface mounted AFC.

First experiments with AFC integrated into glass-fiber reinforced polymer (GFRP) laminates indicated that AFC may well act as initiation sites for defects [6]. Information on longterm reliability of AFC is scant. At Empa, some AFC elements have been used as $\mathrm{AE}$ sensors over a period of about two years, but (a) intermittently, and (b) in laboratory environment. No significant degradation in sensor performance has been noted during that period. Temperature cycling of $\mathrm{AFC}$ between $-40^{\circ} \mathrm{C}$ and $+80^{\circ} \mathrm{C}$ with a period of about 3 hours per cycle also did not yield significant indications of changes in electrical impedance as a function of frequency after more than 250 cycles.

AFC elements integrated into GFRP have also been operated as strain gauges by connecting the output to a coulomb-meter and recording the charge versus time during short-term quasi-static and fatigue loading at various levels of increasing strain [6]. The preliminary results indicate that AFC function as strain gauges up to strain levels around $0.20 \%$. At strain levels of about $0.25 \%$, PZT-fibers start to fragment and the strain gauge functionality degrades. Even though AFC will not be able to compete with conventional resistive strain gauges, it might be interesting to explore a multifunctional application of $\mathrm{AFC}$, e.g., using the element as an $\mathrm{AE}$ sensor and periodically checking whether indications of fiber fragmentation show that a limiting strain of about $0.25 \%$ has been exceeded. Interestingly, about $0.20 \%$ is a typical high level of normal working strain of high-performance carbonfiber reinforced polymer (CFRP) elements in aerospace applications ([7], p. 222).

\section{THE POTENTIAL OF AFC IN MONITORING OF CIVIL ENGINEERING STRUCTURES AND OF INFRASTRUCTURE}

Based on the success for structural integrity assessment of fiber-reinforced composite structures [14, 15], $\mathrm{AE}$ test methods are also being developed for structural integrity assessment of civil engineering structures such as bridge components (e.g., $[20,21]$ ), or of complete bridges [22]. For concrete bridges, laboratory research on $\mathrm{AE}$ monitoring of fracture processes in concrete specimens $[23,24]$ are now followed by first attempts at transferring the technique to real structures [25]. If the conventional AE sensors used in these developments or in prototype applications shall be replaced by AFC, beside cost, three major technical issues have to be considered, namely (1) the appropriate frequency range(s), (2) the long-term performance and reliability, and (3) data reduction, analysis, and transmission. The latter issue does not depend on the use of AFC. Techniques developed for onsite data reduction and wire-less data transmission of signals acquired with conventional AE sensors [26] can directly be applied to data generated by AFC. With respect to the second issue, it is important to assess the long-term performance of $\mathrm{AFC}$, as well as the quality of the acoustic coupling provided by, e.g., adhesive bonding, especially when exposed to relatively harsh outdoor environmental conditions.

In the frequency range between at least 30 to $270 \mathrm{kHz}, \mathrm{AFC}$ with a bandwidth of typically $20 \%$ (corresponding to a few tens of $\mathrm{kHz}$ ) could again directly replace conventional AE sensors in previously developed SHM applications based on $\mathrm{AE}$. Whether AFC could replace sensors in other acoustic methods for SHM of civil engineering structures using frequencies in the tens of $\mathrm{kHz}$ range (e.g., impact-echo [27]) would again be worthwhile to investigate. The determination of eigen-modes or vibration behavior with AFC quite likely would have to rely on their use as strain-gauge [6], and it is questionable whether $\mathrm{AFC}$ would be a cost-effective alternative.

AE monitoring has also been developed for leak detection in pipelines [28, 29]. Again, AFC can directly replace conventional AE sensors. In principle, AFC elements with a characteristic covering the relevant frequency range (between about 20 and $50 \mathrm{kHz}$ ) could be designed (the type of AFC discussed above has its main sensitivity around $50 \mathrm{kHz}$ ). The increased conformability of AFC compared with conventional $\mathrm{AE}$ sensors is a particular advantage in this case. AFC with an active area of $30 \mathrm{~mm} \times 20 \mathrm{~m}$ have been applied directly on pipes with diameters of about $70 \mathrm{~mm}$, without the need for a waveguide that reduces sensitivity. However, long-term behavior and reliability of $\mathrm{AFC}$ and its coupling are again important issues.

A recent study has shown that PZT-patches can be used for impedance-based SHM of pipelines and other structures [30]. 
Due to the limited sensitivity range of impedance monitoring it is important to place the sensors sufficiently close to the area of interest. AFC would, particularly in the case of pipelines, again offer more versatility than planar PZT-patches. This is an example of a potential SHM application for AFC in a nonacoustic test method.

Process monitoring is another area where AFC show potential. As an example, ultrasonic wave reflection monitoring of setting and hardening of concrete [31] can, in principle, be performed with $\mathrm{AFC}$. The preferred in-plane (shear wave) sensitivity and emissivity of AFC, combined with permanent adhesive mounting on a contact plate could yield a versatile sender-receiver even for field application on real structures. The $2.25 \mathrm{MHz}$ centre frequency mentioned in [31] quite likely can not be reached with $\mathrm{AFC}$. Lower frequencies (e.g., below $1 \mathrm{MHz}$ ) are also feasible for this application, provided the pulse length is sufficiently short, and the potential of $\mathrm{AFC}$ in this application should be explored.

The feasibility of integrating (instead of surface mounting) AFC into civil engineering structures such as concrete bridges or bituminous pavement layers has not yet been assessed. Major issues are expected to be mechanical loading during implementation of the AFC and thermal effects from hydration of concrete or application of the bituminous pavements. Investigation of combined thermal and mechanical service loads on AFC of the severity expected for these applications is still pending.

\section{SUMMARY AND OUTLOOK}

Recently developed Active Fiber Composites (AFC) seem well suited as replacements for conventional transducers made of bulk PZT for AE, AU, or impedance monitoring of structures. While their thin, planar design is comparable to that of thin PZT-wafers, the increased conformability of AFC allows for direct mounting on curved surfaces, even with biaxial curvature. Leak detection in pipelines and impedance monitoring of pipe fittings or valves, therefore look promising for developing first SHM applications with AFC.

Frequency tuning of AFC manufactured in one "standard" size, i.e., with a "standard" frequency range of sensitivity and emissivity, simplifying the manufacturing process and hence reducing cost does seem feasible.

The AFC manufacturing process currently employed at Empa has not yet been investigated with respect to cost optimization. Elements are essentially hand-made, one after the other. Cost estimates of raw materials, equipment, and labor indicate that the latter dominates. It is expected that the cost of $\mathrm{AFC}$ will hence be comparable to other sensors that are made in limited numbers involving a relatively large amount of manual labor (e.g., AE sensors). Development of batch or mass production schemes would be subject to demand, but in principle does seem feasible. However, no estimates of potential cost savings can be made at this time. Independently, cost savings are expected in applications of AFC, e.g., from the ease of mounting (eliminating the use of wave-guides on curved surfaces), from the frequency tuning capability, and from permanent adhesive mounting of $\mathrm{AFC}$ versus repeated mounting and removal of more bulky sensors for periodic inspection.

A major limitation for widespread use of AFC in SHM currently is the scant database on long-term behavior and reliability. AFC can be surface-mounted permanently, on both stationary infrastructure and non-stationary structures. Integration into laminates has been achieved but may not be advisable for developing prototype applications, especially those intended for long-term SHM. It would be worthwhile to investigate the problems of applying or integrating AFC into civil engineering structures made of concrete and other construction materials. On one hand, permanent surfacemounted or integrated $\mathrm{AFC}$ eliminate the time-consuming mounting procedure for periodic inspection, and, on the other, in principle, allow for continuous monitoring. In that context, multifunctional use of $\mathrm{AFC}$, such as, e.g., an impact detector based on AE monitoring, combined with evaluation of the defect severity after the event by $A U$ or impedance measurements for high-performance fiberreinforced structural elements looks promising for developing a prototype application of AFC for SHM.

\section{ACKNOWLEDGEMENTS}

The support of A. Belloli of the Institute of Mechanical Systems (IMES) and of B. Schechinger of the Institute of Structural Engineering (IBK) of the Swiss Federal Institute of Technology (ETH) for impedance measurements and $\mathrm{AE}$ sensor characterization, respectively, is gratefully acknowledged. At Empa, L. DeBoni and K. Ruf are acknowledged for technical support for manufacturing and characterization of AFC, and R. Keller for the photographs.

\section{REFERENCES}

[1] Bent, A.A., Hagood, N.W. and Rodgers, J.P., 'Anisotropic actuation with piezoelectric fiber composites', Journal of Intelligent Material Systems and Structures 6 (1995) 338-349.

[2] Bent, A.A. and Hagood, N.W., 'Piezoelectric fibre composites with interdigitated electrodes', Journal of Intelligent Material Systems and Structures 8 (1997) 903-919.

[3] Barbezat, M., Brunner, A.J., Flüeler, P., Huber, Ch. and Kornmann, X., 'A comparison between active and passive piezoelectric elements for damage detection in fiber-reinforced composite laminates', Proceedings Conference on Advanced Technology in Experimental Mechanics, Japan Society of Mechanical Engineers, CD No. JSME 03-207, Paper No. OS09W0089 (2003) 5 p.

[4] Barbezat, M., Brunner, A.J., Flüeler, P., Huber, C. and Kornmann, X., 'Acoustic emission sensor properties of active fiber composite elements compared with commercial acoustic emission sensors', Sensors and Actuators A: Physical 114 (2004) 13-20.

[5] Barbezat, M., Brunner, A.J., Huber, C. and Flüeler, P., 'Integrated active fiber composite elements: characterization for acoustic emission and acousto-ultrasonics', Proceedings, $15^{\text {th }}$ International Conference on Adaptive Structures and Technologies, ICAST 2004, at press (2004). 
[6] Melnykowycz, M., Kornmann, X., Huber, C., Barbezat, M. and Brunner, A.J., 'Performance of Integrated Active Fibre Composites in Glass Fibre Reinforced Epoxy Laminates" (in preparation).

[7] Stazewski, W.J., Boller, C. and Tomlinson, G.R. (editors), 'Health Monitoring of Aerospace Structures: Smart Sensor Technologies and Signal Processing' (John Wiley \& Sons, Chichester, 2004).

[8] Bhalla, S., Soh, C.K. and Liu, Z., 'Wave approach for NDE using surface bonded piezoceramics', NDT\&E International 38 (2004) 143-150.

[9] Sodano, H.A., Park, G. and Inman, D.I., 'An investigation into the performance of macro-fiber composites for sensing and and structural vibration applications', Mechanical Systems and Signal Processing 18 (2004) 683-697.

[10] Brunner, A.J., Barbezat, M., Flüeler, P. and Huber, Ch., 'Composites from piezoelectric fibers as sensors and emitters for acoustic applications', Journal of Acoustic Emission 22 (2004) 127-137.

[11] Kornmann, X. and Huber, C., 'Microstructure and mechanical properties of PZT fibres', Journal of the European Ceramic Society 24 (2004) 1987-1991.

[12] McIntire, P. and Miller, R.K. (eds.), 'ASNT Handbook on Nondestructive Testing, Acoustic Emission Testing', 2 $2^{\text {nd }}$ edition, Vol. 5 (American Society for Nondestructive Testing, 1987).

[13] Kornmann, X., Huber, C., Barbezat, M. and Brunner, A.J., 'Active fiber composites: sensors and actuators for smart composite structures', Proceedings $11^{\text {th }}$ European Conference on Composite Materials, paper No. B074 (2004) 9 p.

[14] ASTM E1067, 'Standard practice for acoustic emission examination of fiberglass reinforced plastic resin (FRP) tanks/vessels', American Society for Testing and Materials International 03.03 (2003) 525-539.

[15] ASTM E 1888/E1888M, 'Standard test method for acoustic emission examination of pressurized containers made of fibreglass reinforced plastic with balsa wood cores', American Society for Testing and Materials International 03.03 (2003) 988-996.

[16] prEN 14584, 'Nondestructive testing - Acoustic emission Examination of metallic pressure equipment during proof testing - Planar location of AE sources', Comité Européen de Normalisation (2002) $14 \mathrm{pp}$.

[17] ASTM E 1495, 'Standard guide for acousto-ultrasonic assessment of composites, laminates, and bonded joints', American Society for Testing and Materials International 03.03 (2003) 844-852.

[18] ASTM E 1736, 'Standard practice for acousto-ultrasonic assessment of filament-wound pressure vessels', American Society for Testing and Materials International 03.03 (2003) 928-932.

[19] Paradies, R. and Hertwig, M., 'Shape control of adaptive composite reflectors', Composites Part B. Engineering 30 (1999) 65- 78 .
[20] ITI Tech report \# 6, 'Acoustic emission monitoring of the trunnion shafts on Oregon DOT bridge \#11377A: I-5 (Interstate) Columbia River east bridge span, Portland, Oregon', Infrastructure Technology Institute, Northwestern University (1994)

[21] ITI Tech report \#18, "Acoustic emission monitoring of north east trunnion shaft on Oregon DOT bridge 1377A I-5 over the Columbia river, Portland, Oregon (update)", Infrastructure Technology Institute, Northwestern University (1996).

[22] Luo, X., Haya, H., Inaba, T., Shiotani, T. and Nakanishi, Y., 'Damage evolution of railway structures by using traininduced AE', Construction and Building Materials 18 (2004) 215-223.

[23] Landis, E.N. and Shah, S.P., 'The influence of microcracking on the mechanical behavior of cement based materials', Advanced Cement Based Materials 2 (1995) 105-118.

[24] Grosse, C., Reinhardt, H. and Dahm, T., 'Localization and classification of fracture types in concrete with quantitative acoustic emission techniques', NDT\&E International $\mathbf{3 0}$ (1997) 223-230.

[25] Ohtsu, M. and Watanabe, H., 'Quantitative damage estimation of concrete by acoustic emission', Construction and Building Materials 15 (2001) 217-224.

[26] Grosse, C.U., Finck, F., Kurz, J.H. and Reinhardt, H.W., 'Monitoring techniques based on wireless AE sensors for large structures in civil engineering', Proceedings $26^{\text {th }}$ Conference of the European Working Group on Acoustic Emission, Vol. BB90-CD, German Society for Nondestructive Testing (2004) 691-698.

[27] Schubert, F., Wiggenhauser, H. and Lausch, R., 'On the accuracy of thickness measurements in impact-echo testing of finite concrete specimens - numerical and experimental results', Ultrasonics 42 (2004) 897-901.

[28] Miller, R.K., Pollock, A.A., Watts, D.J., Carlyle, J.M., Tafuri, A.N. and Yezzi, J.J., 'A reference standard for the development of acoustic emission pipeline leak detection techniques', NDT\&E International 23 (1999) 1-8.

[29] Wood, B.R.A. and Harris, R.W., 'Structural integrity and remnant life evaluation of pressure equipment from acoustic emission monitoring', International Journal of Pressure Vessels and Piping 77 (2000) 125-132.

[30] Peairs, D.M., Park, G. and Inman, D.I., 'Improving accessibility of the impedance-based structural health monitoring method', Journal of Intelligent Materials Systems and Structures 15 (2004) 129-139.

[31] Akkaya, Y., Voigt, T., Subramaniam, K.V. and Shah, S.P., 'Nondestructive measurement of concrete strength gain by an ultrasonic wave reflection method', Mater. Struct. 36 (2003) 507-514. 


6
$\vdots$

